\title{
The Tyranny of Openness: What Happened to Peer Production?
}

\author{
Nathan Schneider \\ University of Colorado Boulder \\ Feminist Media Studies (2021) \\ https://doi.org/10.1080/14680777.2021.1890183
}

This paper examines a "culture war" underway among software peer-production communities through relevant blog posts, legal documents, forum discussions, and other sources. Software licensing has been a defining strategy for peer producers, and much of the conflict at hand revolves around whether licensing should more fully incorporate ethics and economics, respectively. Feminist analysis can aid in tracing the contours of discontent through its emphasis on social processes that enable and infuse productive activity - processes that peer producers have trained themselves to ignore. The emerging critiques, and the experiments they have inspired, gesture toward fuller understandings of what "free" and "open" might mean.

keywords: feminist theory, peer production, commons, free software, open source, software licensing, intellectual property

The author is grateful for feedback on earlier drafts from Michel Bauwens, Heather Meeker, Matthew S. Wilson, and extraordinary anonymous reviewers.

According to a brief trend piece in Wired (Cohen 2018), people in Silicon Valley have been reading "The Tyranny of Structurelessness." The classic essay's author, Jo Freeman, challenged her fellow feminist activists to notice how their insistence on allegedly leaderless, open forms of organization were "becoming a goddess in its own right" (Freeman 1972). In the absence of explicit structures of power, Freeman observed, implicit structures form in 
their place - and can be harder to recognize, challenge, and root out. In the essay's afterlife online, Wired reports, "it is deployed by a wide range of critics to disprove widely held beliefs about the internet as a force of personal empowerment, whether in work, leisure, or politics."

Here I intend to contribute specificity to one dimension of this rude awakening - one with particular affinities to the subject of Freeman's concern in the early 1970s: an emerging debate about the future of software peer production.

Yochai Benkler's foundational account of "commons-based peer production"which I will refer to simply as "peer production" - contended that a mode of open, non-hierarchical, non-market, networked activity would "emerge, if permitted, at the core, rather than the periphery of the most advanced economies" (Benkler 2006, 3). Benkler (2017) maintains this contention more than a decade later. The promise he foresaw has taken hold even in hierarchies and markets. Wikipedia remains a critical backbone of the digital information ecosystem in many languages, and YouTube relies on it to counter misinformation; Linux and other open software communities have won over onetime corporate opponents like Microsoft and IBM (Birkinbine 2020; Delfanti and Söderberg 2018). Cryptographic networks like Bitcoin and its descendants have generated billions of dollars' worth of value from their open code-bases; app-mediated labor markets, promising open access and flexibility, imitate - and, for Benkler (2017), misrepresent - the tropes of peer production in pursuit of a "gig economy."

In the context of a semi-apotheosis, however, some of the central premises of peer production as Benkler identified and theorized it have fallen into contention - not just among the predictable opponents in old-world corporations, but from among peer producers themselves. Diverse critics identify ways in which the logics of peer production facilitate exploitation through unacknowledged forms of power and influence, under the guise of openness (Nafus 2011; A bee with a blog 2020). This paper draws on feminist theory, primarily, to name and explicate a set of inter-related critiques. These critiques share many ambitions for peer production with earlier advocates like Benker and others (Raymond 2001; Lessig 2004; Coleman 2013; Bauwens, Kostakis, and Pazaitis 2019), but they regard certain persistent shortcomings as intolerable flaws. The critiques also echo intersectional and critical race theories (Crenshaw et al. 1995), which have long questioned presumptions of openness and meritocracy in the presence of profound social inequalities. Meanwhile, defenders of the prevailing models of peer production have 
adopted a footing of existential conflict.

I will examine a "culture war" (Klabnik 2019) underway among software peerproduction communities through relevant blog posts, legal documents, forum discussions, and other sources. Software licensing that inverts copyright to turn code into a public resource has been a defining strategy for peer producers (Coleman 2013). Early peer producers encoded (Hall 2001) into licenses and norms an oppositional critique of copyright law, then negotiated a recoding of the movement's meaning that was amenable to industry. Today, a new generation of peer producers is decoding and experiencing those licenses under conditions that constructively distort the original ambitions and unsettle the corporate alliances. Much of the conflict at hand revolves around whether licensing should more fully incorporate ethics and economics, respectively.

I argue that the contours of discontent become clearer through the lens of feminist economic theory, guided by the emphasis that Marilyn Power (2004) places on the tasks of "social provisioning": the social processes that enable and infuse productive activity - and which peer producers have trained themselves to ignore. Feminist analysis thereby helps decipher such intransigent conditions as the demographic homogeneity of peer-production communities, their difficulties in achieving economic sustainability, and their co-optation by hierarchical organizations, particularly large software firms. The emerging critiques, and the experiments they have inspired, gesture toward fuller understandings of what "free" and "open" might mean.

It happens that non-male participants have been among the first to raise alarms, although they vary in their self-identified relationship with feminism (Łapniewska 2016; Meeker 2020). I do not mean to claim that the analysis I offer here describes their personal motivations. What I claim, rather, is that feminist theory enables an oppositional decoding that draws connections not otherwise apparent.

Prevailing discourses and practices of software peer production have shunned even conventional economic analysis, avoiding wherever possible explicit engagement with such concerns as capital ownership, labor contracting, and shared asset management. As a result, peer producers have outsourced economic concerns to non-peer capitalist firms, which have been willing to absorb some responsibility in order to reap the economic benefits. While seeking to secure an abstract commons of intellectual property, peer producers have overlooked the material and social substrates that any feats of intellect inevitably require. 
I offer this study as an invitation for peer producers to adopt feminist analysis more into their self-understanding and possible futures. In what follows, I begin with an overview of recent, overlapping crises among peer producers related to software licensing. I will then examine these crises in conversation with feminist economic theory, followed by proposals for the future of peer production and directions for future study. Just as Jo Freeman called her fellow activists to rather conventional forms of structural accountability in their organizations, the agitators in these high-tech communities raise old questions of power, ethics, and economics.

\section{"The age of license proliferation"}

On February 24, 2020, the renowned programmer, firearms enthusiast, and self-described hacker Eric S. Raymond posted a message to the Open Source Initiative's License-Discuss email list. "A wild co-founder appears," the subject line announced, referring to Raymond's role in first establishing OSI in 1998. The message began, "After twenty years of staying off this list, I have joined it" (Initiative 2020). In a post two days later, after calling an opponent a "toxic loonytoon," Raymond wrote:

Make no mistake; we are under attack. If we do not recognize the nature of the attack and reject it, we risk watching the best features of the open-source subculture be smothered by identity politics and vulgar Marxism.

This latter post was soon removed (Schestowitz 2020), and on February 28 the Open Source Initiative board banned Raymond from the list for violating its code of conduct.

During Raymond's four-day Second Coming to OSI, he raised a series of concerns about proposals to adjust the organization's standards for software licensing to accommodate matters of "fairness" and "ethical open source." Raymond was not alone in perceiving a sense of crisis. Less spectacularly, but just as significantly, Raymond's OSI co-founder Bruce Perens had already announced that he was canceling his membership in the organization two months earlier, on January 2 (Claburn 2020). The previous year, softwarelicense enthusiasts had blogged about "the culture war at the heart of open source" (Klabnik 2019) and "the great open source shake-up" (Downing 2019). According to attorney Kate Downing, "The computing world has changed and moved on while open source hasn't." Without further explanation, and in passing, programmer Steve Klabnik noted, "I personally think that gender 
plays a huge role."

Perhaps it is not incidental that the \#MeToo movement had recently found its way into software peer production; in 2019, fallout from ties between the billionaire sex offender Jeffrey Epstein and the MIT Media Lab enveloped Free Software Foundation founder Richard Stallman and Creative Commons founder Lawrence Lessig. A year earlier, the notoriously blunt Linux founder Linus Torvalds took a hiatus from leading Linux development, as one journalist put it, "to work on himself and try to stop being a dick" (Jones 2018). But the questions that precipitated Raymond's frustration preceded the Epstein scandal. They take form most directly in the legal contrivances that constitute the basis of Open Source: software licenses. The carefully crafted assumptions behind these licenses were now under threat in a new "age of license proliferation" (Kuhn 2018).

The challenges to foregoing patterns of Open Source licensing come in the realms of ethics, on the one hand, and economics on the other. Perhaps it is not incidental, also, that while as many as 95 percent of Open Source contributors identify as men (GitHub 2017), the principal license proliferators in each realm are women.

\section{The ethical challenge}

Coraline Ada Ehmke is a software developer, a longtime participant in the community surrounding the programming language Ruby. She has also become well known for her activism, most of all since coming out to the Ruby community as transgender in 2013. The following year, she created the Contributor Covenant, "a code of conduct for open source projects" (Ehmke 2014a). The Covenant offers a brief set of guidelines for recognizing and addressing toxic behavior. Hundreds of thousands of Open Source projects have adopted it, including Ruby and Linux, although early on in her efforts, Open Source leaders took the idea of a code of conduct as a bureaucratic affront (Ehmke 2014b). Despite their communities' oftenstaggering homogeneity along economic, gender, and racial lines, these leaders tended not to believe that participants' conduct was to blame.

Ehmke was running for a board seat at OSI during the Eric S. Raymond incident, and Raymond (2020b) referred to her among "our enemies" at the time. (He addressed the aforementioned "toxic loonytoon" comment to her as well.) By then, she had a new project, the Ethical Source Movement (Ehmke 2020), which proposed a new set of provisions for Open Source 
licenses relating to how licensed software may be used. The Ethical Source website features licenses that prohibit violations of, respectively, the Universal Declaration of Human Rights, International Labour Organization standards, and the "global climate response." Users of software so licensed risk legal action if they use the software in a way that crosses the particular ethical lines that the developers have defined.

Ethical Source represents a critical departure from OSI's primary product, the Open Source Definition, whose sixth of ten criteria is "No Discrimination Against Fields of Endeavor." This is an article of faith among peer-production licensing regimes: Don't go down the slippery slope of restricting uses. "The freedom to run the program as you wish, for any purpose" is the foundational number zero of the Free Software Foundation's "four essential freedoms" (Stallman 2019; Rand-Hendriksen 2020). Outside of software licenses per se, Wikipedia editors aspire to "a neutral point of view," eschewing personal opinion, judgment, or partisanship (Wikipedia 2020). Early in Raymond's brief return to the OSI discussion lists, he wrote:

This is really what I joined the list to say. ... I initiated the founding of OSI so it could pursue and defend freedom. Thomas Paine had an apposite quote: "He that would make his own liberty secure, must guard even his enemy from oppression; for if he violates this duty, he establishes a precedent that will reach to himself." ... With whatever moral authority I still have here, I say to all advocates of soi-disant "ethical" licensing not just "No" but "To hell with you and the horse you rode in on." (Raymond 2020a)

Bruce Perens (2019) further expressed concerns about whether an ethically restrictive license could be enforceable, reflecting on past experiences with using licensing to enforce a boycott against the South African police under Apartheid; he held that such harms should be addressed through criminal law, not through licensing intellectual property. The question of enforcement has long worried Open Source advocates, who have sought to prevent a deluge of boutique licenses from making all open licenses harder to enforce (Kuhn 2018). While Ehmke and her allies continued seeking guidance from lawyers to improve Ethical Source licenses, she stressed that the intervention has symbolic import regardless of its legal power. "Even if no one listens to us, there's value in saying we don't want our software used in this way," she told Business Insider (Chan 2019).

The Ethical Source Movement, first introduced in 2019, came at a time of 
growing concern about the ethics of software use. Google employees had protested their company's engagement in military contracts and censorship in China, and developers attempted to block Microsoft-owned GitHub's contract with the US Immigration and Customs Enforcement agency (Chan 2019). In 2020, Seneca-Cayuga artist and technologist Amelia Winger-Bearskin called for "ethical dependencies," drawing on indigenous traditions, that could short-circuit such abuses through code (Winger-Bearskin 2020). Matters of ethics inclined some to dispense with the "open" ideal altogether. "Open Source is morally problematic," concluded one developer-blogger (GoodmanWilson 2019). "Open Is Cancelled," declared another, referencing the public shaming of so-called "cancel culture," and proposed exchanging the focus on openness for solidarity, "rooted in kindness, compassion, and mutual respect" (A bee with a blog 2020). As these broadsides and Raymond's ferocity indicate, the ethical challenge threatened core commitments about the meaning of "open" in Open Source.

\section{The economic challenge}

While working on this paper, I was contacted by a distressed acquaintance at a small, cash-strapped nonprofit that creates software for local sustainability initiatives. She explained that a famous tech company had begun using her organization's software, without paying for it, to create bespoke products for customers. Her organization had adopted an Open Source license because Open Source seemed aligned with its public-benefit mission. Now, she perceived this use-case as exploitation and wondered if there was any recourse. I had to reply that it was exactly what the license enables. This is part of what it means by openness.

As if with such a case in mind, the seventh and final provision of the Ethical Source Definition stipulates that an ethical license "encourages fair compensation":

The software project's maintainers may, at their discretion, request remuneration in the form of code contributions, financial consideration, or other forms of voluntary support from organizations that derive commercial value from the software.

While modest, this is a departure. Richard Stallman (2019) famously (for license enthusiasts) distinguished between freedom as in "free beer" and "free speech"- emphasizing that Free Software refers to free flows of information and holds no position on economic flows. Open Source took this logic 
even further, dispensing with the language of "free" in order to better appeal to corporate partners (Morozov 2014). For works other than software, Creative Commons offers a "NonCommercial" licensing option, which enables somewhat more fine-grained economic control. But Free and Open Source do not permit distinguishing among external entities - whether corporations or charitable foundations or individual developers - that might use, develop, or fund licensed projects. Technology firms have increasingly shown willingness to step in, through contributions of employee time and grants to entities such as the Linux and Apache foundations. But these commitments are piecemeal and indirect, and they present the risk of distorting communities toward corporate priorities. Critics have also blamed the absence of direct compensation in software peer production for persistent failures to attract contributors with less access to disposable income and time not consumed with paid or care work (Anonymous Author 2015; Burns 2016). Focusing on free speech alone outsources the economics that, one way or another, are necessary to provision contributor labor.

The question of "sustainability" in software peer production has been a persistent matter of anxiety and study (e.g., Arp et al. 2018; Eghbal 2020), stemming from the challenge of forming a business model around publicly available software. Initiatives such as Gitcoin, GitHub Sponsors, Liberapay, and Open Collective have sought to create economic infrastructure for software communities, particularly through enabling recurring donations from supporters or "bounties" that fund specific contributions. But solutions remain elusive. Even among blockchain-based projects, which generally do have an explicit economics in their open code through tokenization, incentives steer developers toward proprietary services rather than shared utilities. Perhaps, as Benkler (2006) suggests, the commons and the market are to be forever at odds.

The new "age of license proliferation" proposes to involve economics at the level of licensing. While the Ethical Source Definition goes only so far as inviting "voluntary support," another thread of licensing experimentation has sought to ensure that certain commercial uses of peer-produced software requires remuneration of the producers. A leading figure in this effort has been Heather Meeker, a lawyer who pioneered writing economics into licenses with Open Source businesses and activists alike. She does not identify with the Ethical Source camp. "I am simply rarely inclined to impose my views on particular issues of the day upon others," she explains (Meeker 2020).

Commercially minded variations on peer-production licenses have been in use 
since the origins of Free Software and Open Source in the 1990s (Valimaki 2003). One such practice, known as "dual licensing" or "proprietary relicensing" (Kuhn 2020), involves offering software under both an OSI-compliant license and, for a price, a more permissive license that enables integration into proprietary systems. The companies behind the Open Source database projects MySQL and Berkeley DB employed this approach more than two decades ago. Other Open Source-oriented companies, such as Red Hat, chose to rely on income from service contracts to support their software development. But both business models are in danger of running aground with the turn to "cloud computing," in which organizations increasingly rely on just a handful of firms to operate their computing services (Thompson 2019); since fewer enterprise clients manage their own servers, there is shrinking demand for service contracts and proprietary licenses. The most visible example of this phenomenon has been MongoDB, a database company that received no compensation when its Open Source product became part of the offerings of Amazon Web Services. MongoDB then developed and adopted the Server Side Public License, which requires a cloud provider like Amazon to make the source code of its entire "stack" of software services open and accessible in order to use the licensed software. Amazon responded by deploying its own MongoDB-like database.

Heather Meeker represented MongoDB when it created the Server Side Public License in 2018. The same year, she was part of the team that drafted the Commons Clause, an add-on to familiar Open Source licenses that converts them into "source available" licenses: the source code is open and available to all, but the right to commercialize the licensed software is not. A year later, Meeker led the development of the PolyForm Project, a website whose initial version offered five different software licenses for various business models; these include a "free trial" license and licenses that restrict use to noncommercial and small-business purposes, respectively.

The gatekeeping authorities for peer-production licenses - namely, the Free Software Foundation and Open Source Initiative - have thus far not certified licenses that impose new restrictions on commercial use. "I have had plenty of awkward interactions with those in the free software movement," Meeker (2020) says, "who have occasionally told me outright that what I do is immoral." Stallman (2010) has acknowledged the potential benefits of duallicensing arrangements. Yet other partisans contend, as Bradley M. Kuhn (2020) of the Software Freedom Conservancy puts it, that "this business model has a toxic effect on copyleft at every level"; commercial licensing could encourage developers to prioritize paid, proprietary uses of the software over 
the commons-facing version. Fershtman and Gandal (2007) found empirically that restrictive licensing correlates with lower output per contributor than more business-friendly licenses. Further restrictions - whether economic or ethical - could stifle vibrant peer production.

The outcomes might differ, however, if there were a more explicit economics built into peer production, rather than a structurelessness that relies on the beneficence of outside structures. Could it be that the absence of an economic layer was simply an oversight, encoded into the techniques of software peer production among a founding cohort of largely male programmers with access to unusual quantities of self-directed time?

\section{Social provisioning}

Feminist social theory bears insights especially well suited for interpreting the tribulations in software peer production. While figures such as Benkler and Lessig have had to stretch conventional economic and legal theories to encompass peer production, feminist tradition is in more familiar territory. Feminist economics has long examined the category of abundance - especially relevant, given software's capacity for near-zero-cost replication and circulation - as opposed to economists' conventional preoccupation with scarcity (Strober 1994). Feminist thinkers have also studied practices of commoning (Federici 2004), while conventional theories tended to see only privately owned and government-managed resource pools. Women and feminist perspectives meanwhile played a significant, overlooked role in the early development of computing cultures (Rankin 2018). While men like Eric S. Raymond receive most of the credit for its origins, the term "open source" was coined by a woman, Christine Peterson (Morozov 2014).

For a feminist-informed consideration of "the great open source shake-up," I will rely on Marilyn Power (2004)'s summary of feminist economic thought in terms of what she calls "social provisioning" - an emphasis on how social practices structure the distribution of resources and rewards. Power identifies five "methodological starting points," which I paraphrase as follows:

- Recognizing hidden care and domestic labor in economic life

- Prioritizing human well-being alongside other metrics of wealth

- Correcting for unequal access to power and agency

- Asserting the validity and inescapability of ethical judgment

- Intersecting gender analysis with that of race, class, and other forms of identity 
In the following, I build on an ongoing feminist critique of male-dominated spaces in contemporary tech cultures. This critique has been well surveyed, for instance, in SSL Nagbot (2016) and elsewhere in the Journal of Peer Production, the online magazine Model View Culture, and the Geek Feminism Wiki. Sophie Toupin (2014) offers a vital precedent in her analysis of feminist hackerspaces as a constructive counterpoint to prevailing hackerspace cultures. I hope this interpretation of the licensing debates contributes to the recognition that feminist perspectives help explain emergent practices and contradictions in peer production communities. I am not claiming that feminist thinkers - or women - speak with one voice on this or any other subject; my claim is only that feminist thought lends a coherence to debates about peer production that have otherwise confounded many participants.

A further reference point is the legacy of political economist Elinor Ostrom. Although Ostrom did not explicitly identify her work with feminism or employ gender as a guiding concept, she was the first woman to win the Nobel Memorial Prize in Economic Sciences, and her pioneering research on the management of "common-pool resources" recognized otherwise obscured economic practices in which women often play leading roles (Łapniewska 2016). These practices have been of growing interest among researchers of digital cultures and communities. Her work may be read as a crusade against illusions of structurelessness - pointing out, as it does, the ways in which communities that might seem ostensibly amorphous actually employ wellcrafted and isomorphic structures (Ostrom 1990, 2006). She highlights, for instance, the importance for communities of boundary-making, of clear and malleable rules, and of mechanisms for dispute resolution and sanctioning rulebreakers. Open Source communities have frequently rejected such practices as cumbersome and antiquated, yet Ostrom's work indicates that they do so at their peril.

In this section, I will turn to Power's five "starting points" of social provisioning, alongside Ostrom's logic of commoning, to demonstrate the coherence in the shake-up at hand. In particular, social provisioning reveals basic barriers and inequities in peer production communities that may not be visible in transactions of code or technical email-list discussions.

\section{Recognizing undervalued labor}

Feminist analysis highlights forms of work that dominant norms otherwise ignore or undervalue. This includes family-member care and houseworktheorized as reproductive labor (Federici 2012; Jarrett 2014) or shadow 
work (Illich 1981; Menzies 1997) — upon which waged labor rests. Even in the realm of compensated work, norms have long classified jobs associated with women - from needlework to early (human) "computers" - as unskilled, even if they may take many years to master (Phillips and Taylor 1980; SSL Nagbot 2016). Feminists have felt and studied the disguised abuses of "flexible" work arrangements long before there was an online gig economy (Cady 2013), recognizing patters such as the extra "second shift" of unpaid domestic work that women often confront after a shift in the paid workforce (Hochschild and Machung 2012). Patterns of work that society devalues have taken new forms in peer production processes. Feminized labor here includes the emotional work of managing online communities (Terranova 2000; Nakamura 2015) and what practitioners Mullins and Cooke (2015) identify as the devaluing of "non-coding contributors in open source," which they contend causes frustrations that "ultimately force members to move on and potential ones to never join." While male-dominated communities may regard their homogeneity as perpetually confounding, its causes are no mystery in the context of feminist thought.

Both the ethical and economic challenges to the dominant licensing regimes raise questions of under-compensated labor. The Ethical Source Definition invites voluntary compensation from institutional users; the Commons Clause and PolyForm licenses variously restrict commercialization in order to encourage paid re-licensing contracts. These efforts assume that the usual business models around peer production are insufficient, particularly if they benefit some contributors out of proportion to others - such as those whose employers pay them to contribute, or who gain employment through their leisure-time contributions. Rather than seeking to insulate the software commons from transactional concerns, these projects seek to embed fair transactions into the nature of the commons. In this sense they resemble a kind of digital "wages for housework" campaign (Federici 2012), seeking to name a form of exploitation by demanding that its otherwise hidden economy come out into the open. Yet wages are only one dimension of a just economic life.

\section{Prioritizing well-being}

Raymond (2020b) insisted on "the right to be rude" after his removal from the OSI mailing lists: "the degenerative slide into suppression of disfavored opinions has to be stopped right where it starts, at the tone policing." He singles out the advent of codes of conduct in Open Source projects and 
denounces Coraline Ada Ehmke, the most visible promulgator of such codes. What he perceives as policing tone, he writes, "damages our self-correction process" - a process that has been a core feature of Open Source's value proposition to corporate patrons (Raymond 2001; Morozov 2014). This celebration of hostility, tellingly, came at a time of unprecedented worker protests and walk-outs against sexist harassment and discrimination at big tech companies such as Google and Amazon-hand-in-hand with demands for ethical constraints on the products the workers were required to build (Tarnoff 2020).

Codes of conduct present a modified value proposition: that more diverse participants will mean better self-correction and more inclusive design. Writes Ehmke (2014b): "Codes of conduct are, in part, intended to communicate that organizers put a priority on the safety and comfort of marginalized members of the community." These codes also reject tendencies to regard rudeness and more extreme forms of abuse as individual faults rather than emanations from social norms (Harris, McFarlane, and Wieskamp 2020). Feminist economics thus regards well-being less as a matter of individual utility maximizing than of community choice. Ostrom also stressed that clear and fairly enforced rules are essential for managing common resource pools. Peer producers, like anyone else, need a stable and trustworthy stage in order to freely contribute.

\section{Correcting for inequalities of agency}

Powers's third starting point centers around the capacity to act. In the vein of critical race scholars' refusal to accept as meritocratic a system that exhibits consistently oppressive outcomes (Crenshaw et al. 1995), Ehmke rejects the celebration of meritocracy that prevails in software peer-production communities (Ehmke 2014b, 2015). Her "Post-Meritocracy Manifesto" contends that "meritocracy has consistently shown itself to mainly benefit those with privilege, to the exclusion of underrepresented people in technology" (Ehmke 2018). In addition to outright exclusion, she finds that the feminization of "soft" skills such as community management keeps women out of the "hard" coding skills that the alleged meritocracy more highly regards. Joseph Reagle (2017) refers to the kind of meritocracy commonly practiced in Open Source a "naive meritocracy," holding out the possibility of a truer, and truly open, meritocracy. For these critics, the guise of meritocracy disguises real inequalities of access and agency among peer producers.

Reagle (2013) stresses the tendency of Open Source communities to tolerate 
sexist behavior and speech, in effect discouraging women from active participation while emboldening men. Another frequently cited form of inequality lies in access to the leisure time necessary for non-salaried peer production, a resource distributed unequally along lines of gender and class (Rose 2019). Strategies to develop a more explicit economy for peer production could help ensure that people with less access to leisure time can be compensated for their contributions.

One further dimension of agency, which Ostrom highlighted, is the need for autonomy from external authorities and organizations - to ensure, for instance, that participants can help craft their own standards of excellence, rather than simply adopting those of outside funders or norms. But crafting such standards means having processes for deliberation and decision, as well as the power to enforce what the community decides.

\section{Asserting ethical judgment}

Andrew Ross (2006) summarized the state of intellectual-property activism at the time as "voices proclaiming freedom in every direction, but justice in none." Both the Free Software and Open Source camps passionately celebrate the free flows of abstract information and the user-rights of users, while abandoning responsibility for the human impacts of their software. Powers, in contrast, stresses that feminist thought insists on the need to hold space for ethical reasoning, particularly in apparently technical and quantitative domains. Feminist scholars have articulated epistemologies such as standpoint theory (Harding 2012) and "situated knowledges" (Haraway 1988) that challenge claims to ethical neutrality - contending that such claims themselves carry ethical freight. The hostile defenses of neutrality and freedom from figures such as Raymond seem to support the feminist contention. The difference might be summarized as one between an ethics of information flows and an ethics of social effects.

While some ethical challengers conclude that Open Source is "broken" or "cancelled," Ehmke stresses that information ethics and social ethics need not be mutually exclusive but that they should coexist. She frequently celebrates what Open Source has achieved through information freedoms and hopes for more through the addition of social ethics. The motto on the Ethical Source Movement's website is "Open Source, Evolved." Yet this evolution means being open in new ways and more closed in others. 


\section{Intersecting identities and setting boundaries}

Feminists have long recognized that claims of neutrality in Open Source communities obscure norms that devalue non-male work (Nafus 2011). Among the feminist hackerspaces that Toupin (2014) chronicles, a defining feature might seem like a sin against openness: practices of "boundary setting" by excluding membership according to gender identity, or what Savic and Wuschitz (2018) call a "separatist attitude." In articulating a feminist separatism that incorporates intersecting forms of marginalization, Toupin quotes the Black feminist theorist bell hooks (1990):

I am located in the margin. I make a definite distinction between that marginality which is imposed by oppressive structures and that marginality one chooses as site of resistance - as location of radical openness and possibility.

Hackerspaces formed among people with marginalized identities, Toupin shows, seek not merely assimilation into the tech industry's status quo, but a recognition of the distinctive insights and gifts that come from the margins. To allow those experiences - those standpoints and situations - to have the freedom to express themselves fully, hackers have seen fit to establish spaces of distinction. They find new freedoms by placing constraints on openness and, as hooks describes, making possible a new openness in turn. Ostrom, too, found that a critical ingredient for common resource management was boundary-making.

Freeman wrote "The Tyranny of Structurelessness" for the feminist "rap groups" of the early 1970s, the largely women-only spaces for solidarity and "consciousness-raising" that emboldened Second Wave feminists to achieve gains in public and economic life. These groups arose in the wake of 1960s activist formations that were allegedly open but persistently male-dominated and hierarchical. In order to work toward societies that were truly open to them, they had to draw lines and close doors.

Does some well-considered door-closing constitute, as Raymond puts it, an "attack"? The frame of social provisioning reveals how the unrest in Open Source emerges from a cluster of basic concerns that peer production communities have taught themselves to treat as invisible or inadmissible. It remains to be seen whether Open Source can stretch to incorporate more of its participants' humanity. 


\section{Conclusion: From tyranny to commons}

Open Source has become a widespread mode of software development in corporate, civic, and academic settings alike. Microsoft's 2018 acquisition of GitHub for $\$ 7.5$ billion and IBM's acquisition of Red Hat for $\$ 34$ billion the following year indicate success, at least in financial terms. Yet this success has not been widely felt in most users' experience of technology or its economic flows. "The year of the Linux desktop" - the eschatological event (turned inside joke) when a community-developed operating system would finally go mainstream - has arrived only through Google's Linux-based Android and Chromebook products. To the extent peer production has thrived, it has continued to rely on the corporate firm to supply (and capture) its economics. Rather than diminishing the stature of the firm, as predicted (Benkler 2006, 2017), software peer production may be further intensifying corporate power, lowering the cost of technologies that support mass data collection and user manipulation, such as through Google's Linux-based operating systems and Linux-based server farms. That peer producers are asking hard questions about ethics and economics should thus not come as a surprise.

I have argued that a feminist lens aids in decoding the otherwise vexing upheavals that have recently consumed the discourse surrounding Open Source. Of particular usefulness are longstanding feminist concerns around making hidden economies explicit and critiquing the ethical content embedded in claims of ethical neutrality. The institutional gatekeepers for Open Source and Free Software may or may not decide to re-encode their licensing standards with any of the proposed alternatives; regardless, the underlying critiques go to the heart of the broader project of peer production. If peers are to produce usefully and sustainably together, surely they will bring their ethics to the work and require an economics in return.

Benjamin J. Birkinbine has called for "subversive commoning" based on the recognition that "commons-based movements will actively need to work to subvert capital logics" $(2020,114)$. Like the clever subversion of intellectualproperty law that is the basis of all "copyleft" licensing, the next subversions should be radical without being utopian. They should draw people, for this-worldly reasons, into new productive paradigms.

Rather than continually adding restrictions, peer production licensing regimes might be rethought from the ground up to cultivate a deeper reciprocity. Perhaps, to begin with, the focus on intellectual-property licensing is an inadequate frame, and peer producers should turn toward other techniques. 
That is, if peer production is to displace the firm as the dominant mode of organizing production, it should have the capacity to offer a parallel economy and a parallel ethics. Licenses alone are probably inadequate to the task.

Visions of parallel institutions for peer producers have been theorized and experimented on in such terms as "open value networks" (Siddiqui and Brastaviceanu 2013) or "open cooperatives" (Bauwens and Kostakis 2014). In these models, peer production is not peripheral to the firm, but provides the logic for the firm itself. These kinds of approaches introduce a new social contract for productive activity, one in which contributors create public commons while also receiving remuneration in proportion to the assessed value of their contributions. Contributors also hold governance rights within a project and have a say over its internal priorities and external partnerships.

Blockchains and related distributed-ledger technologies offer tantalizing techniques for supplanting the industrial firm with "distributed autonomous organizations" (Swartz 2017). They employ public code-bases to run networks, often with built-in "token economics" and governance mechanisms. For instance, platforms such as CoMakery propose to reward peer producers with a tokenized financial stake in the projects they contribute to. Among financially successful blockchain projects, contributors have already garnered significant rewards. Yet blockchain communities have tended to repeat - even amplify - the demographic monotony and endemic sexism present elsewhere in software peer production (Penny 2018). Their governance systems tend to privilege financial interests over other concerns, such as ethical ones. In response, a document called the DisCO Manifesto (Troncoso and Utratel 2019) proposes "distributed cooperative organizations," insisting that using technology like blockchains does not absolve communities of the need for building an inclusive culture and intentional relationships. The DisCO model explicitly applies feminist economics, such as by incorporating non-market care work as part of its accounting methods. Technology, no matter how open or decentralized, is no substitute for confronting intersecting inequalities directly, naming them and creatively unraveling them, in spaces where collective reflection and collective action are possible.

A logic of "subversive commoning" should begin with ensuring that economies of peer production no longer flow principally through external corporations or individuals, but through the projects' own common pools. Doing so turns these projects into polities, producing space for ethical reasoning and requiring appropriate, well-structured self-governance.

Thus far, the prevailing governance logic in software peer production has 
been along the lines of the "benevolent dictator for life," as Linux's Linus Torvalds is commonly described (Schneider 2021). An "Open Governance Index" found a severe lack of inclusive processes guiding major Open Source projects (Laffan 2012). There are exceptions, such as the Debian Project's constitutional democracy and the Apache Software Foundation's ban on "dictators" and "corporate overlords." But strenuous commoning requires more serious attention to basic practices of accountable governance. A noteworthy example is the Python community, which, in the wake of its founder's resignation after decades as a benevolent dictator, voted to adopt a five-member elected board (Edge 2018). To support sustainability, IBM has called for developer-elected leadership of Open Source projects (Moore and Ferris 2020). Having explicit and responsive systems of governance is a prerequisite both for managing common resources and for enabling the kinds of ethical discourse that Open Source activists are increasingly demanding. A commons must have a means of discerning the common good.

I hope to have offered reasons for taking seriously the upheavals underway in software peer production and an invitation for further study. For instance, there is need for more empirical investigations of the dynamics of participation - particularly in terms of under-valued labor - in peer production communities. Second, as new approaches to software licensing emerge, they should be treated as opportunities for research and experimentation, rather than merely as grist for ideological combat. Finally, there is need for research on legal structures and funding models for open cooperatives and the like, which seek to extend the territory of peer production from hacking intellectual property to reimagining the firm - a territory better suited to serve as a nexus of economics, ethics, and governance.

The critiques and innovations now besieging software peer production are asking more of this movement than it presently offers. The achievements thus far in licensing are remarkable but not sufficient. If peer production is to challenge dominant norms of economy and culture, it can no longer refuse to call those norms into question.

\section{Disclosures}

While working on this article, I was invited to join the Ethical Source Working Group and did so. 


\section{References}

A bee with a blog. 2020. "Open Is Cancelled." Medium. https://medium.com/@beewithablog/openis-cancelled-da7dd6f2aaaf.

Anonymous Author. 2015. "The Hidden Power Dynamics of Open Source." Model View Culture, August.

Arp, Laurie Gemmill, Megan Forbes, Robert T. Cartolano, Tom Cramer, Michele Kimpton, Katherine Skinner, and Ann Baird Whiteside. 2018. "It Takes a Village: Open Source Software Sustainability." LYRASIS.

Bauwens, Michel, and Vasilis Kostakis. 2014. "From the Communism of Capital to Capital for the Commons: Towards an Open Co-Operativism." tripleC: Communication, Capitalism \& Critique 12 (1): 356-61. https: //doi.org/10.31269/triplec.v12i1.561.

Bauwens, Michel, Vasilis Kostakis, and Alex Pazaitis. 2019. Peer to Peer: The Commons Manifesto. University of Westminster Press. https://doi. org/10.16997/book33.

Benkler, Yochai. 2006. The Wealth of Networks: How Social Production Transforms Markets and Freedom. New Haven, CT: Yale University Press.

. 2017. "Peer Production, the Commons, and the Future of the Firm." Strategic Organization 15 (2): 264-74. https://doi.org/10.1177/ 1476127016652606.

Birkinbine, Benjamin J. 2020. Incorporating the Digital Commons. University of Westminster Press. https://doi.org/10.16997/book39.

Burns, Terri. 2016. "Side Project Culture: Opportunities and Obstacles for Marginalized People in Tech." Model View Culture, March.

Cady, Kathryn A. 2013. "Flexible Labor." Feminist Media Studies 13 (3): 395-414. https://doi.org/10.1080/14680777.2012.678876.

Chan, Rosalie. 2019. "Software Freedom Vs Human Freedom: A Surge of Activism Is Rocking Open Source Developers, as Programmers Fight to Stop Their Software from Being Used for 'Evil'.' Business Insider, December.

Claburn, Thomas. 2020. "Bruce Perens Quits Open Source Initiative Amid Row over New Data-Sharing Crypto License: 'We've Gone the Wrong Way with Licensing'." The Register, January. 
Cohen, Noam. 2018. “A 1970s Essay Predicted Silicon Valley's High-Minded Tyranny." Wired, November.

Coleman, E. Gabriella. 2013. Coding Freedom: The Ethics and Aesthetics of Hacking. Princeton: Princeton University Press.

Crenshaw, Kimberlé, Neil Gotanda, Garry Peller, and Kendall Thomas. 1995. Critical Race Theory: The Key Writings That Formed the Movement. The New Press.

Delfanti, Alessandro, and Johan Söderberg. 2018. "Repurposing the Hacker: Three Cycles of Recuperation in the Evolution of Hacking and Capitalism." Ephemera: Theory and Politics in Organization 18 (3): 457-76.

Downing, Kate. 2019. "The Great Open Source Shake-up.” Law Offices of Kate Downing.

Edge, Jake. 2018. "Python Gets a New Governance Model." LWN.net. https://old.lwn.net/Articles/775105/.

Eghbal, Nadia. 2020. Working in Public: The Making and Maintenance of Open Source Software. Stripe Press.

Ehmke, Coraline Ada. 2014a. "Contributor Covenant: A Code of Conduct for Open Source Projects." https://www.contributor-covenant.org/.

—. 2020. "The Ethical Source Movement." https://ethicalsource.dev.

- 2014b. "Codes of Conduct: When Being Excellent Is Not Enough." Model View Culture, December.

- 2015. "The Dehumanizing Myth of the Meritocracy." Model View Culture, May.

—. 2018. "The Post-Meritocracy Manifesto." https://postmeritocracy.org/.

Federici, Silvia. 2004. Caliban and the Witch. Brooklyn, NY: Autonomedia.

- 2012. Revolution at Point Zero: Housework, Reproduction, and Feminist Struggle. 1 edition. Oakland, CA : Brooklyn, NY : London: PM Press.

Fershtman, Chaim, and Neil Gandal. 2007. "Open Source Software: Motivation and Restrictive Licensing." International Economics and Economic Policy 4 (2): 209-25. https://doi.org/10.1007/s10368-007-0086-4. 
Freeman, Jo. 1972. "The Tyranny of Structurelessness." Berkeley Journal of Sociology 17: 151-64.

GitHub. 2017. "Open Source Survey." Open Source Survey. https://opensourcesurvey.org/2017/\#data.

Goodman-Wilson, Don. 2019. "Open Source Is Broken." https://don.goodmanwilson.com/posts/open-source-is-broken/.

Hall, Stuart. 2001. "Encoding/Decoding." In Media and Cultural Studies: KeyWorks, edited by Meenakshi Gigi Durham and Douglas M. Kellner. Vol. 2. Malden, MA: Blackwell.

Haraway, Donna. 1988. "Situated Knowledges: The Science Question in Feminism and the Privilege of Partial Perspective." Feminist Studies 14 (3): 575-99. https://doi.org/10.2307/3178066.

Harding, Sandra. 2012. "Feminist Standpoints." In Handbook of Feminist Research: Theory and Praxis, 46-64. Thousand Oaks, CA: SAGE Publications, Inc. https://doi.org/10.4135/9781483384740.n3.

Harris, Kate Lockwood, Megan McFarlane, and Valerie Wieskamp. 2020. "The Promise and Peril of Agency as Motion: A Feminist New Materialist Approach to Sexual Violence and Sexual Harassment." Organization 27 (5): 660-79. https://doi.org/10.1177/1350508419838697.

Hochschild, Arlie, and Anne Machung. 2012. The Second Shift: Working Families and the Revolution at Home. New York, NY: Penguin.

hooks, bell. 1990. Yearning: Race, Gender, and Cultural Politics. Boston, MA: South End Press.

Illich, Ivan. 1981. Shadow Work. Boston: Marion Boyars.

Initiative, Open Source. 2020. "License-Discuss Archive." http://lists.opensource.org/pipermail/licensediscuss_lists.opensource.org/2020-February/thread.html.

Jarrett, Kylie. 2014. "The Relevance of 'Women's Work': Social Reproduction and Immaterial Labor in Digital Media." Television 83 New Media 15 (1): 14-29. https://doi.org/10.1177/1527476413487607.

Jones, Rhett. 2018. "Linux Founder Takes Some Time Off to Learn How to Stop Being an Asshole." Gizmodo, September.

Klabnik, Steve. 2019. "The Culture War at the Heart of Open Source." Steve Klabnik on Svbtle. https://words.steveklabnik.com/the-culture-war-at- 
the-heart-of-open-source.

Kuhn, Bradley M. 2018. "Toward Community-Oriented, Public \& Transparent Copyleft Policy Planning." Software Freedom Conservancy. https://sfconservancy.org/blog/2018/oct/16/mongodb-copyleftdrafting/.

- 2020. "Toward Copyleft Equality for All." Software Freedom Conservancy. https://sfconservancy.org/blog/2020/jan/06/copyleft-equality/.

Laffan, Liz. 2012. "A New Way of Measuring Openness: The Open Governance Index." Technology Innovation Management Review 2 (1): 18-24.

Łapniewska, Zofia. 2016. "Reading Elinor Ostrom Through a Gender Perspective." Feminist Economics 22 (4): 129-51. https://doi.org/10. 1080/13545701.2016.1171376.

Lessig, Lawrence. 2004. "The Creative Commons Commentary." Montana Law Review 65 (1): 1-14.

Meeker, Heather. 2020. "Personal Correspondence." Email.

Menzies, Heather. 1997. "Telework, Shadow Work: The Privatization of Work in the New Digital Economy." Studies in Political Economy 53 (1): 103-23. https://doi.org/10.1080/19187033.1997.11675317.

Moore, Todd, and Chris Ferris. 2020. "Open Governance: It's All About Community." IBM Developer. https://developer.ibm.com/articles/opengovernance-community/.

Morozov, Evgeny. 2014. "The Meme Hustler." The Baffler, April.

Mullins, Stacy, and Jesse Cooke. 2015. "Non-Coding Contributors in Open Source." Model View Culture, February.

Nafus, Dawn. 2011. "'Patches Don't Have Gender': What Is Not Open in Open Source Software:" New Media E Society, November. https: //doi.org/10.1177/1461444811422887.

Nakamura, Lisa. 2015. "The Unwanted Labour of Social Media: Women of Colour Call Out Culture as Venture Community Management." New Formations 86 (86): 106-12. https://doi.org/10.3898/NEWF.86.06.2015.

Ostrom, Elinor. 2006. Understanding Institutional Diversity. Princeton, NJ: Princeton University Press. 
. 1990. Governing the Commons: The Evolution of Institutions for Collective Action. Cambridge, UK: Cambridge University Press.

Penny, Laurie. 2018. "Four Days Trapped at Sea with Crypto's Nouveau Riche." BREAKERMAG, December.

Perens, Bruce. 2019. "Sorry, Ms. Ehmke, the 'Hippocratic License' Can't Work." https://perens.com/2019/09/23/sorry-ms-ehmke-the-hippocraticlicense-cant-work/.

Phillips, Anne, and Barbara Taylor. 1980. "Sex and Skill: Notes Towards a Feminist Economics." Feminist Review 6 (1): 10. https://doi.org/10. 1057/fr.1980.20.

Power, Marilyn. 2004. "Social Provisioning as a Starting Point for Feminist Economics." Feminist Economics 10 (3): 3-19. https://doi.org/10.1080/ 1354570042000267608.

Rand-Hendriksen, Morten. 2020. "Value Neutrality and the Ethics of Open Source." MOR10.

Rankin, Joy Lisi. 2018. A People's History of Computing in the United States. Cambridge, MA: Harvard University Press.

Raymond, Eric S. 2001. The Cathedral $\&$ the Bazaar: Musings on Linux and Open Source by an Accidental Revolutionary. Sabastopol, CA: O'Reilly Media.

. 2020a. "[License-Discuss] "Ethical Open Source" and the Persona Non Grata Clause."

—. 2020b. "The Right to Be Rude." Armed and Dangerous.

Reagle, Joseph. 2013. "'Free as in Sexist?' Free Culture and the Gender Gap." First Monday. https://doi.org/10.5210/fm.v18i1.4291.

- 2017. "Naive Meritocracy and the Meanings of Myth." Ada: A Journal of Gender, New Media, and Technology, no. 11. https://doi.org/ 10.7264/N34Q7S9N.

Rose, Julie L. 2019. Free Time. Princeton, NJ: Princeton University Press.

Ross, Andrew. 2006. "Technology and Below-the-Line Labor in the Copyfight over Intellectual Property." American Quarterly 58 (3): 743-66.

Savic, Selena, and Stefanie Wuschitz. 2018. "Feminist Hackerspace as a Place of Infrastructure Production." Ada: A Journal of Gender, New 
Media, and Technology, no. 13.

Schestowitz, Roy. 2020. "How OSI Co-Founder Got Banned from the OSI's Mailing Lists (a Month After the Other Co-Founder Resigned in Protest in Those Mailing Lists, Bemoaning Attacks on Software Freedom)." Techrights.

Schneider, Nathan. 2021. "Admins, Mods, and Benevolent Dictators for Life: The Implicit Feudalism of Online Communities." New Media \& Society. https://doi.org/10.1177/1461444820986553.

Siddiqui, Yasir, and Tiberius Brastaviceanu. 2013. "Open Value Network: A Framework for Many-to-Many Innovation." Montreal, Canada: Sensorica.

SSL Nagbot. 2016. "Feminist Hacking/Making: Exploring New Gender Horizons of Possibility." Journal of Peer Production, no. 8 (March).

Stallman, Richard. 2010. "On Selling Exceptions to the GNU GPL." Free Software Foundation. https://www.fsf.org/blogs/rms/selling-exceptions.

- 2019. "What Is Free Software?" Free Software Foundation. https://www.gnu.org/philosophy/free-sw.html.

Strober, Myra H. 1994. "Rethinking Economics Through a Feminist Lens." The American Economic Review 84 (2): 143-47.

Swartz, Lana. 2017. "Blockchain Dreams: Imagining Techno-Economic Alternatives After Bitcoin." In Another Economy Is Possible: Culture and Economy in a Time of Crisis, edited by Manuel Castells, 82-105. Cambridge, UK: Polity.

Tarnoff, Ben. 2020. The Making of the Tech Worker Movement. Logic Magazine.

Terranova, Tiziana. 2000. "Free Labor: Producing Culture for the Digital Economy." Social Text 18 (2 (63)): 33-58. https://doi.org/10.1215/ 01642472-18-2_63-33.

Thompson, Ben. 2019. "AWS, MongoDB, and the Economic Realities of Open Source." Stratechery. https://stratechery.com/2019/aws-mongodband-the-economic-realities-of-open-source/.

Toupin, Sophie. 2014. "Feminist Hackerspaces: The Synthesis of Feminist and Hacker Cultures." Journal of Peer Production, no. 5 (October). 
Troncoso, Stacco, and Ann Marie Utratel. 2019. "DisCO Manifesto." Disco.coop.

Valimaki, Mikko. 2003. "Dual Licensing in Open Source Software Industry." Systemes dInformation et Management 8 (1).

Wikipedia. 2020. "Wikipedia:Role of Jimmy Wales." Wikipedia, July.

Winger-Bearskin, Amelia. 2020. "Indigenous Wisdom as a Model for Software Design and Development." Mozilla Foundation. https://foundation.mozilla.org/en/blog/indigenous-wisdom-modelsoftware-design-and-development/. 